\title{
Modular Plant Opens up New Flexibility
}

A contract coater wants to expand. A suitable industrial hall can be found quickly. After it has been refurbished, a highly efficient, modular powder coating system is being set up there, which today provides the surface expert a wide range of flexibility.

As one of the largest contract coating companies in Saxony, Limbacher Oberflächenveredelung $\mathrm{GmbH}$ (LOV) offers its customers the full range of metal, plastic and wood coatings. The company has been growing steadily since it was founded in 1998 and currently works with
63 employees in three shifts. The team around managing director Uwe Jentsch has committed itself to a high level of coating quality and is among other things a GSB Master member.

Because the capacities at the Limbach location were increasingly reaching their limits and more and more orders had to be rejected, Jentsch had been looking for an external opportunity of expansion for a long time.

LOV is a partner of the local "manufacturing network" in which seven Saxon companies bundle their know-how and

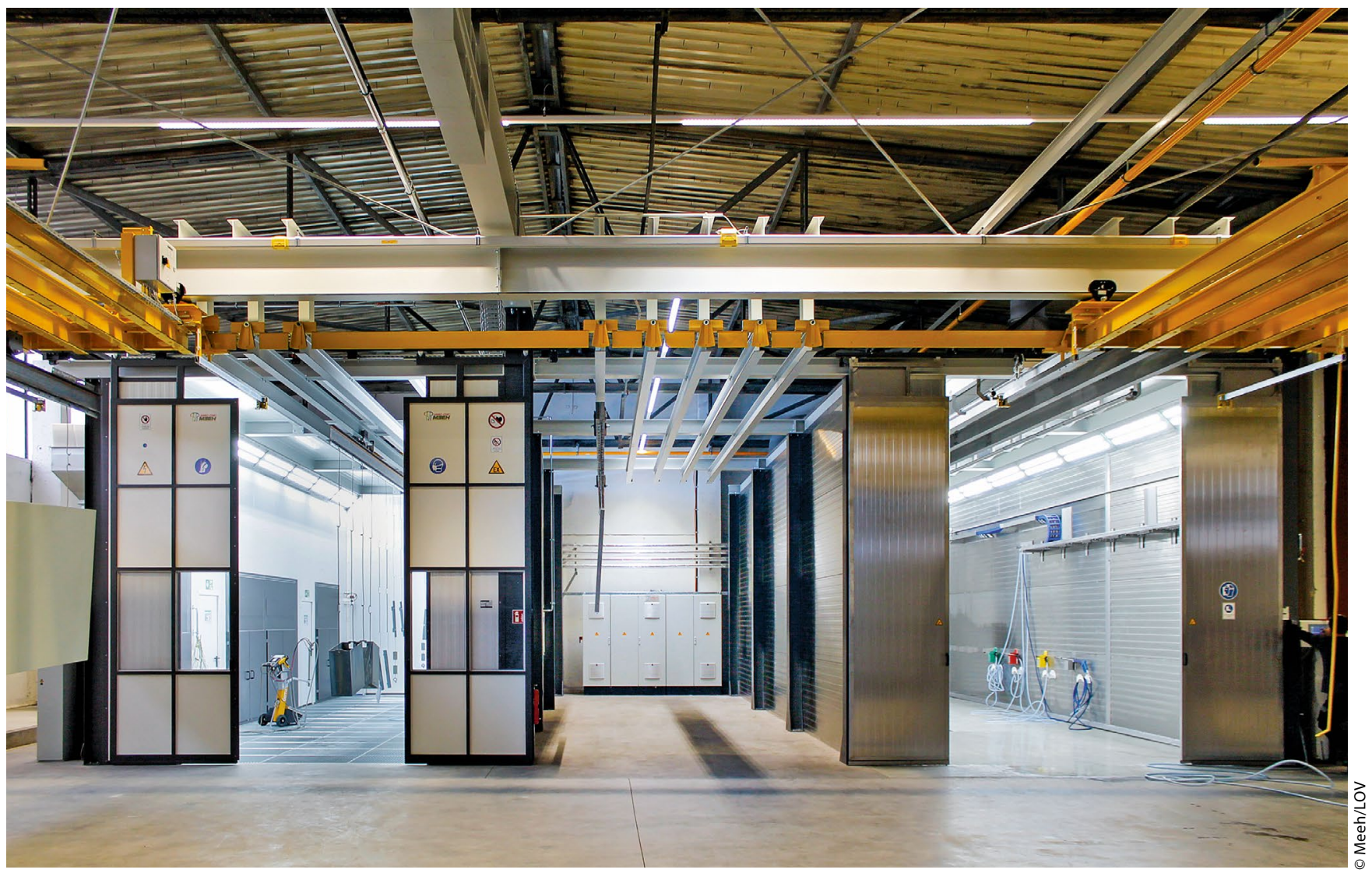

Powder, cooling and washing booth: Thanks to its low-carry-over design, the washing booth allows aluminum and steel to be pretreated separately. Up to ten processes can be carried out here, from rinsing to passivation. 


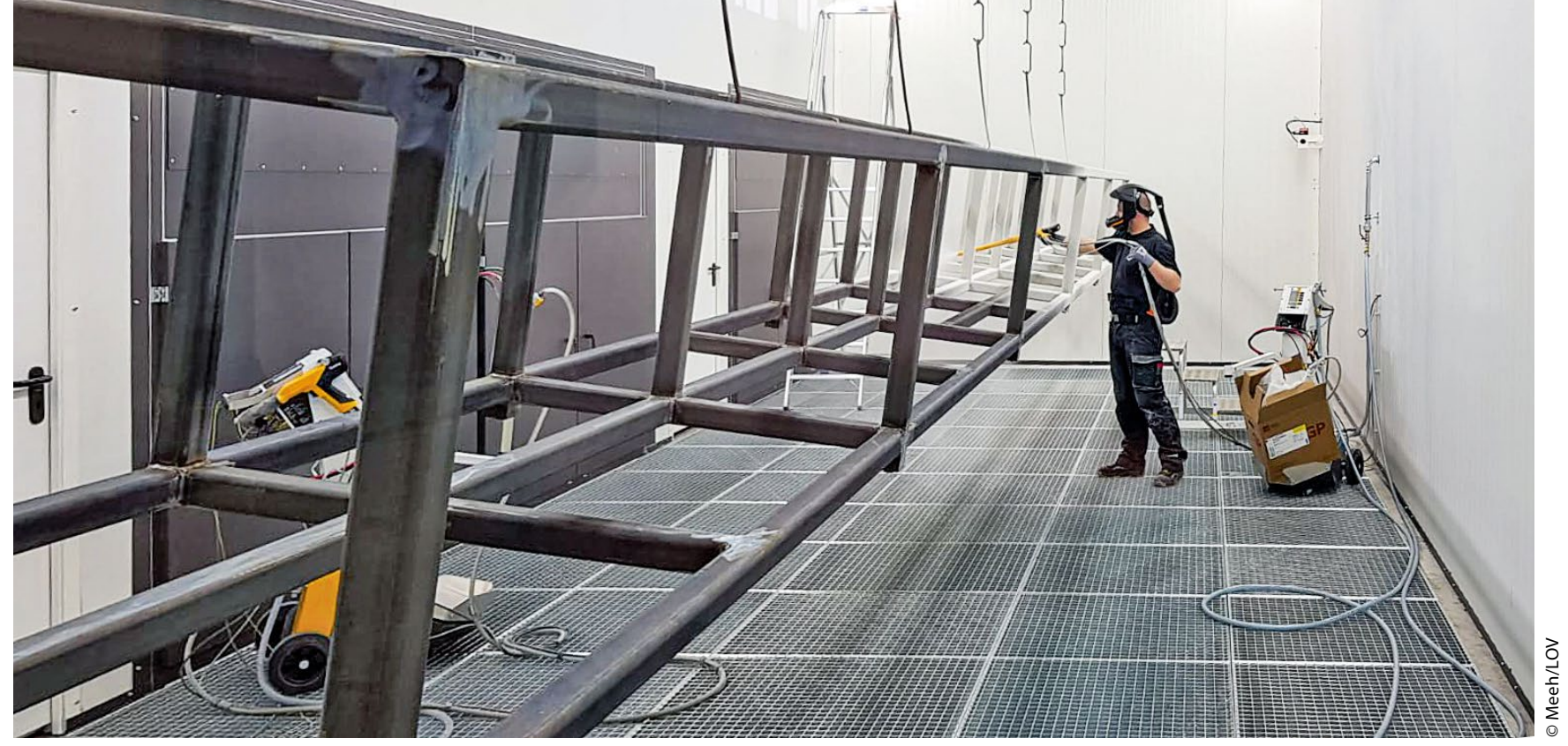

The dimensions of the booth allow undisturbed working and increase the coating window to $10,000 \times 2500 \times 3000 \mathrm{~mm}$.

jointly implement industrial projects from, among other things, mechanical engineering, rail and special vehicle construction or medical technology. One of these partners, Schwalbe Metallbau from nearby Mülsen, offered enough space for the first LOV branch at its location in an empty industrial hall. Schwalbe and LOV not only work closely together in the network: "We generate around a fifth of our annual sales with Schwalbe," explains LOV Quality Manager Jörg Seiche. In this respect, intensifying the cooperation at a common location was of great mutual interest.

\section{Positive experiences}

But before things could really get going, the LOV team completed several brainstorming sessions: "We thought about which technology we would need in the long term in order to better meet the needs of our customers and to gain new customer groups with unique selling propositions. We then very quickly came to the realization that our ideas can be best implemented with the modular design of the jumbo coat systems." explains Jentsch. The coating specialist had already successfully implemented a previous project in a team with Meeh. For Jörg Seiche, the great reliability of the system manufacturer also plays an important role: "When we converted our wet paint shop in 2017, we had a time window of exactly four weeks and not a day more; our coating was temporarily outsourced to another company.

The Meeh company had promised us the completion including handover for December 20th - and that was exactly how it went: four days before Christmas everything was finished, the plant could go into operation. “

The LOV team then set various priorities for the plant technology at the new production site. These included:
- Maintaining and expanding the highquality standards at both locations

- Maximum possible redundancy between the two systems.

- Increased flexibility in the processing of small, medium and large orders.

- Securing regional unique selling points with regard to coating windows, part weights and part geometry

- Increase in efficiency through the optional and parallel use of manual and automatic coating.

- Use of state-of-the-art environmentally and resource-saving technology.

\section{Simple structure, sophisticated details}

In search of further ideas, the surface experts looked at various Meeh plants in the area. "There are many jumbo coat models here, but each one is unique in its own way and always tailored to the specific requirements of the customer. They are

\section{POLISH YOUR KNOWLEDGE} WITH THE NEW IST EMAGAZINE

Your eMagazine is now available at: www.emag.springerprofessional.de/ist

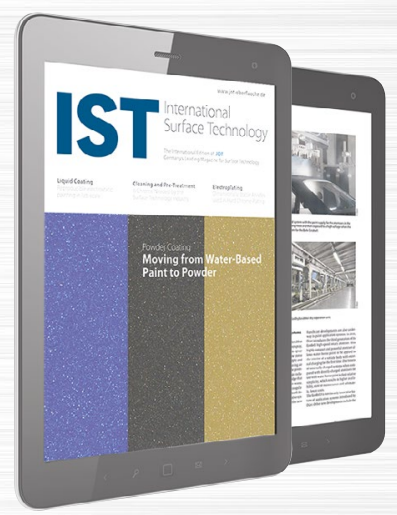




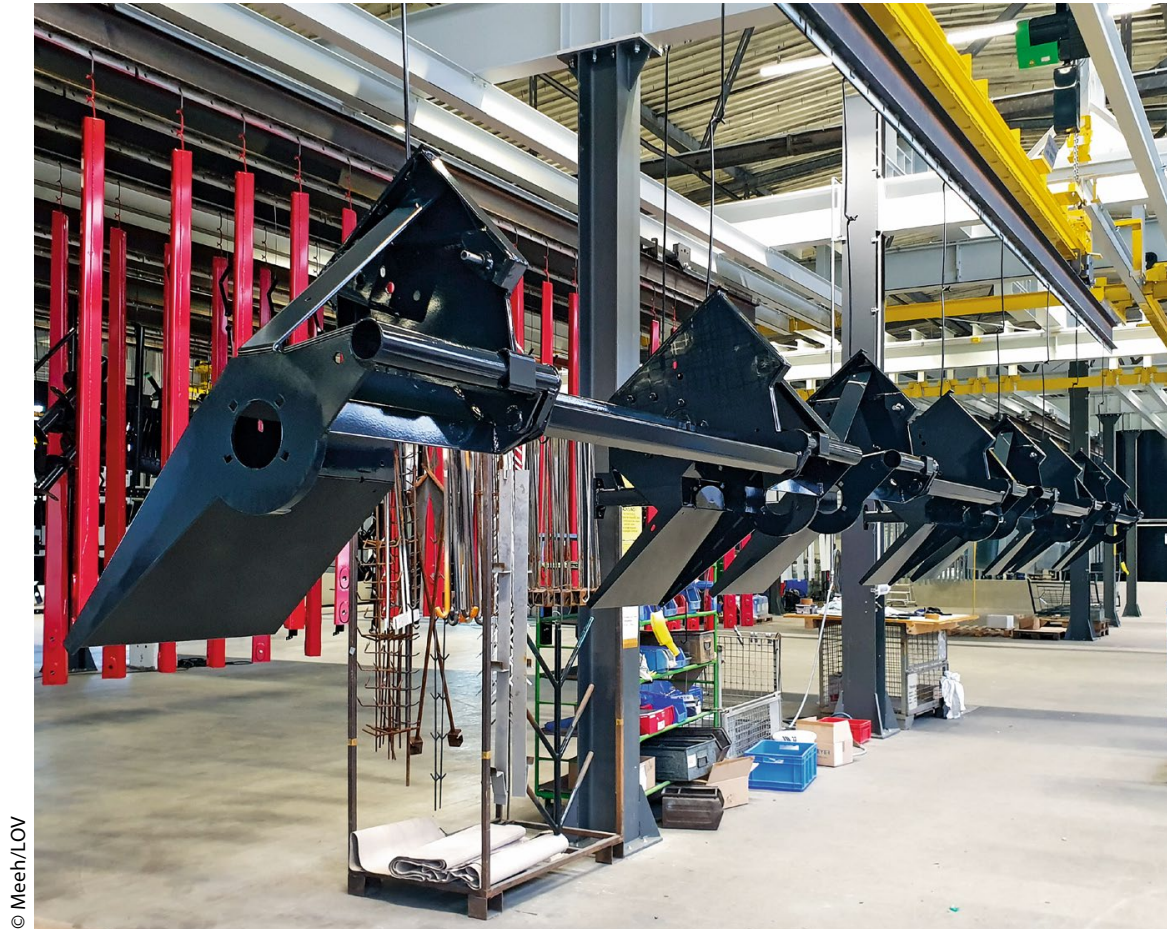

quite simple in structure, but the details are right." emphasizes Seiche. Nobody produces this principle at this maturity like Meeh.

Finally, in February 2020 and so in time before the outbreak of the pandemic, the decision was made in favor of the highly efficient, modular jumbo coat technology, consisting of:

- Large parts powder spray booth with floor suction
- Automatic powder spray booth

- Powder dryer (indirectly gas-heated)

- Adhesive water dryer (identical in construction to powder dryer, due to redundancy)

- Stainless steel washing cabin (automatic / manual)

- Manual sliding track with three electric transverse travelling platforms

- Two lifting-lowering stations

- Hartmann evaporator system
Two lifting and lowering stations are also integrated into the modular powder coating system, which optimize the handling of the parts to be coated

With it, the coating window was increased to $10,000 \times 3000 \times 3000 \mathrm{~mm}$ (length $\times$ width $\times$ height) and the part weight to $2 \mathrm{t}$. The former warehouse had to be completely renovated before the plant was built.

Among other things, the industrial hall got a completely new hall floor, office fittings and a visually appealing, thermally insulated outer facade. All plant-related media were completely reinstalled.

\section{Evaporators and ion exchangers deliver fully demineralized water}

Thanks to its low-carry-over design, the washing booth allows aluminum and steel to be pretreated separately. Up to ten processes can be carried out here, from rinsing to passivation. Because carryover is otherwise always an issue in chamber pretreatment, Jentsch and Seiche decided on a cascading control of the pretreatment chemistry, in which the baths fill up automatically over several basins. LOV chose NABU as its supplier, which also

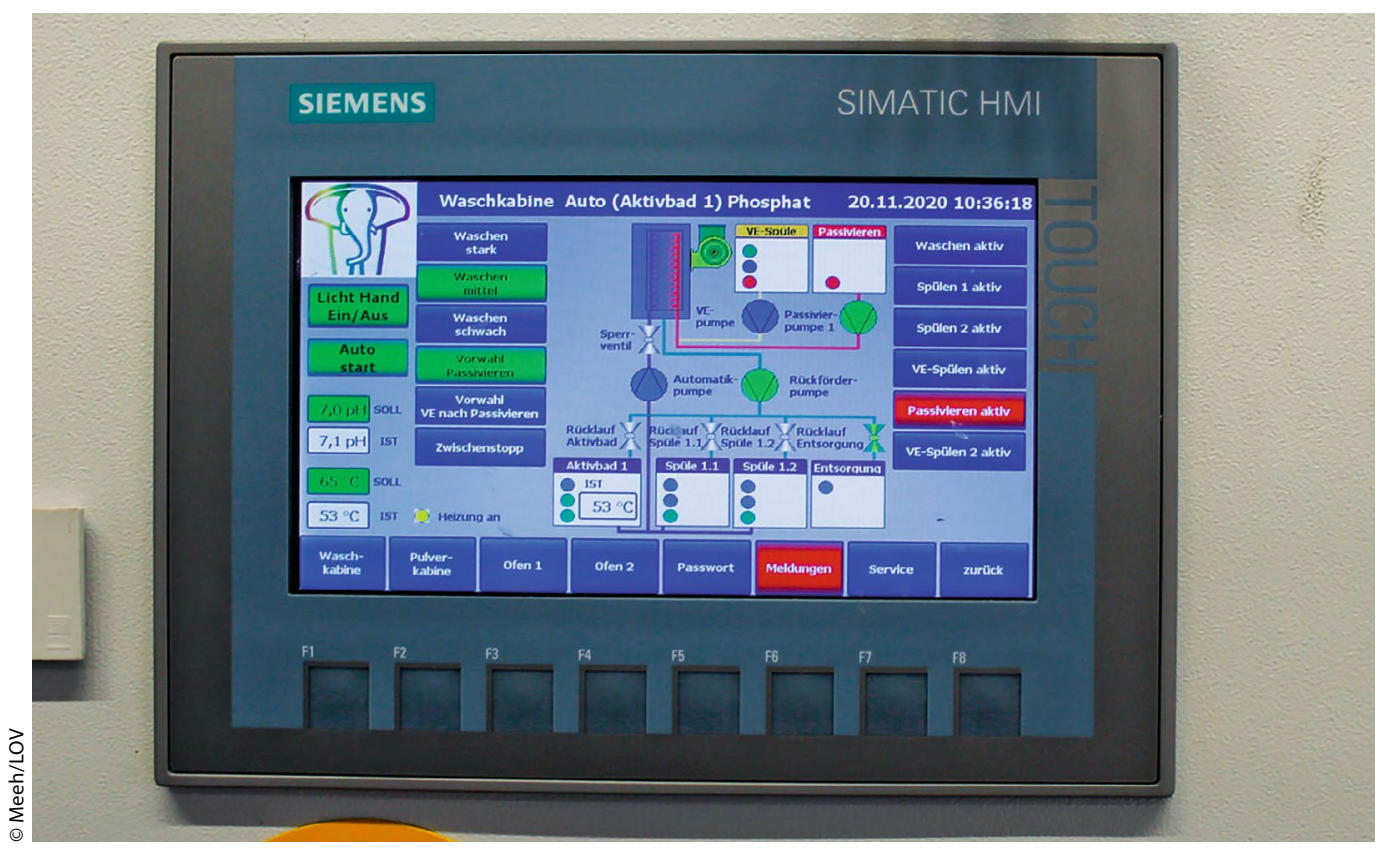

A control panel with a wellstructured user interface provides an overview of all processes. 
supplies the headquarters in LimbachOberfrohna. „For us, this means easier warehousing, and the employees are already very familiar with the chemistry. Quality assurance for both locations runs centrally in Limbach.” says Seiche. All process wastewater is recycled to pure deionized water using an evaporator and ion exchanger from Hartmann. The separated dirt concentrate is disposed of by environmental services. This means that the coating processes are not only completely free of waste water, but the surface specialist also always has enough water available for the final sink. The deionized water quality is 10 to $15 \mu \mathrm{S}$.

\section{Expandable in all directions}

The Construction of the plant began in April 2020 in compliance with all safety and distance precautions. Operations started in June. As usual with Meeh plants, the plant supplier provided a chief installation technician who carried out the assembly together with a selected LOV team. It was practically made-tomeasure work - the ovens fit exactly under the hall beams to the millimeter, as do the high $12 \mathrm{~m}^{3}$ storage tanks of the evaporator system.

Despite the corona virus, the system was completed with all its peculiarities without delay. The dual powder booth system enables both automatic powder coating for flat parts and manual coating for complex part geometries.

Thanks to its modular concept, the plant can grow at any time and thus also enables other process variants. Additional components can be added at any time. The system is also resistant to unplanned fluctuations in orders and personnel. In an emergency, it can also be operated with just two employees.

The official inauguration of the new painting technology took place in Mülsen on October 2nd, 2020. As managing director Jentsch reports, word got around quickly, LOV regularly receives inquiries from new potential customers. Thanks to the investment, the coating experts can now react flexibly and no longer have to reject orders, not even when coating requirements fluctuate seasonally. //

\section{Contact}

\section{MEEH Pulverbeschichtungs- und}

\section{Staubfilteranlagen $\mathbf{G m b H}$}

Wimsheim (Germany)

info@jumbo-coat.de

www.jumbo-coat.de

\section{LOV GmbH}

Limbach Oberfohna (Germany)

Uwe Jentsch

jentsch@lov.de

Jörg Seiche

seiche@lov.de

www.lov.de

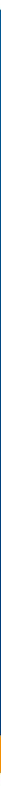

\section{Scan \& Spray - Programming-free coating of any shape!}

The second generation of Dynamic Contour Detection detects the object contour fully automatic and positions the guns individually even for thin objects and at high conveyor speeds. Due to the programming-free adaption of all relevant line settings the application range is significantly extended to the most complex of components and geometries. 